Article

\title{
The Effects of Urban Sprawl and Industrial Agglomeration on Environmental Efficiency: Evidence from the Beijing-Tianjin-Hebei Urban Agglomeration
}

\author{
Dong Feng ${ }^{1} \mathbb{0}$, Jian $\mathrm{Li}^{1,2}$, Xintao $\mathrm{Li}^{1, *}$ and Zaisheng Zhang ${ }^{1}$ \\ 1 College of Management and Economics, Tianjin University, Tianjin 300072, China; \\ fengdong@tju.edu.cn (D.F.); lijian631219@163.com (J.L.); zhangzs@tju.edu.cn (Z.Z.) \\ 2 Research Center for Circular Economy and Enterprise Sustainable Development, \\ Tianjin University of Technology, Tianjin 300384, China \\ * Correspondence: t391753064@tju.edu.cn; Tel.: +86-151-2214-2277
}

Received: 5 April 2019; Accepted: 24 May 2019; Published: 29 May 2019 updates

\begin{abstract}
Environmental efficiency evaluation is an effective way to assess the synergetic development degree between the economy and environment. In order to realize the mechanism of the effects of urban sprawl and industrial agglomeration on environmental efficiency by using the super efficiency Slacks-based Measure (SBM) model with undesirable outputs, this paper firstly calculates the environmental efficiency of the 13 cities in the Beijing-Tianjin-Hebei urban agglomeration from 2006 to 2017. Then, based on the panel data of the 13 cities, we empirically examine the influence of urban sprawl and industrial agglomeration on environmental efficiency by adopting the panel Tobit regression model. The results show that large gaps exist in the degree of the cities' environmental efficiency in the research period, and only Beijing's environmental efficiency exhibits full efficiency in the 13 cities, with the overall environmental efficiency of the Beijing-Tianjin-Hebei urban agglomeration presenting a decreasing trend. Additionally, the Tobit regression results indicate that urban sprawl has a significantly negative impact on environmental efficiency, but with the continual improvement of industrial agglomeration, the negative effects of urban sprawl will be partially offset. From the regression results of control variables, economic growth and urbanization developments have an inhibiting effect on the promotion of environmental efficiency. Furthermore, industrial structure optimization and technological innovation are helpful to improve environmental efficiency. The opening-up policy has had a significantly positive impact on environmental efficiency, and the "pollution paradise" hypothesis was untenable in the Beijing-Tianjin-Hebei urban agglomeration.
\end{abstract}

Keywords: urban sprawl; industrial agglomeration; environmental efficiency; Super efficiency SBM model; panel Tobit regression model

\section{Introduction}

In the past 40 years of reform and opening up to the outside world, the miracle of China's economic growth has been the reciprocal development of industrialization and urbanization. Like many countries, the urbanization process has strengthened the dilemma between environmental protection and economic growth. This predicament is mainly caused by industrial development because of its important role in energy consumption [1]. The rapid development of industrialization and urbanization has brought about a series of problems, such as urban sprawl, environmental deterioration, and tight resource constraints, while promoting China's economic transformation and industrial agglomeration. At present, China is in a crucial developmental stage, where industrialization 
is in the middle and later stages and urbanization is accelerating. As the world's largest manufacturing country and the second largest economy, China's urbanization rate has also increased from $17.9 \%$ in 1978 to $58.5 \%$ in 2017, with an average annual growth rate of one percentage point, and the level of urbanization has increased significantly. However, at the same time, China has also become the world's largest emitter of greenhouse gases [2]. The contradiction between the social economy and ecological environment is still the primary problem for China to realize sustainable development. The sustainability of economic development and environmental protection is largely related to the improvement of efficiency in the production process-that is, the economic efficiency of environmental factors needs to be analyzed, which is environmental efficiency [3]. For this reason, the Chinese government actively advocates the vigorous development of a green economy [4].

Since China has a vast territory and there are regional differences at the level of economics, resource endowment, geographical environment, and development policies, it is difficult for all the regions to achieve the green development goals set by the state in the same way [5]. Urban agglomeration, as the main form of China's new urbanization planning and construction, has an increasingly higher strategic status. The in-depth advancement of major national development strategies, such as the synergetic development of the Beijing-Tianjin-Hebei regions and the construction of the Yangtze River Economic Belt to establish a new mechanism for coordinated regional development with urban agglomeration as the main body, is an important measure for China's adherence to the path of green development. Among the various areas of development, the Beijing-Tianjin-Hebei urban agglomeration, as the capital urban agglomeration, has become the region with the most intense human-natural relationship and the most serious contradiction between overloaded resources and the environment [6]. "The Outline of Synergetic Development of Beijing-Tianjin-Hebei" proposes that Beijing-Tianjin-Hebei synergetic development should first make breakthroughs in key areas, such as transportation integration, ecological environmental protection, and industrial upgrading and transfer. In this context, this paper selects the Beijing-Tianjin-Hebei urban agglomeration as the research object, firstly measures its environmental efficiency, and then mainly analyzes the impact of urban sprawl and industrial agglomeration on environmental efficiency. The findings are expected to provide a reference for the formulation of more reasonable and effective industrial and environmental policies in the process of Beijing-Tianjin-Hebei synergetic development and to realize the goal of building Beijing-Tianjin-Hebei cities into a world-class urban agglomeration with an optimized spatial layout, good ecological environment, and developed economy and culture.

\section{Literature Review}

With the rapid development of industrialization and urbanization in the world, studies on industrial agglomeration and urban sprawl have become a hot issue in academic circles. Industrial agglomeration is an important phenomenon in the regional economy, and its accumulative effect is beneficial to economic development, but its crowded effect could also cause excessive energy consumption and pollutant emissions to increase, thereby aggravating environmental pollution [7]. Some studies have shown that industrial agglomeration can significantly improve urban labor productivity and total factor productivity [8-10] and promote the sustainable development of urbanization through industrial support and factor agglomeration [11-13]. However, the acceleration of urbanization has led to the emergence of urban sprawl. Urban sprawl refers to the phenomenon of the disordered expansion of urban space in the process of urbanization, which makes the economic activities originally concentrated in the urban core area spread to the peripheral areas, and the urban form is characterized by decentralization, a low density, a multicenter, and more reliance on vehicle commuting [14], which also has a significant impact on economic development, energy consumption, and environmental pollution [15-17]. After Grossman and Krueger proposed the hypothesis of the "environmental Kuznets curve (EKC)" [18], the relationship between industrial agglomeration and urban sprawl on environmental pollution began to receive extensive attention from scholars, and fruitful research results have been achieved. 
Lin Boqiang and Liu Xiying pointed out that China's current stage characteristics of urbanization and industrialization would have an important impact on its energy consumption and the resulting greenhouse gas emissions [19]. Through data analysis of 200 cities in the EU, Frank et al. found that the expansion of industrial agglomeration aggravated environmental degradation [20]. Ottaviano et al. also pointed out that excessive industrial agglomeration would worsen environmental quality and increase the cost of environmental governance [21]. Zeng and Zhao's study showed that manufacturing agglomeration could alleviate the "pollution paradise" effect [22]. Liu et al. used statistical data from 285 cities, from 2004 to 2013, to analyze the effect of industrial agglomeration on energy efficiency. The spatial autocorrelation tests showed that there is significant spatial autocorrelation and spatial heterogeneity in urban energy efficiency [23]. However, some scholars have shown that the impact of industrial agglomeration on environmental pollution is not a simple linear relationship [24,25]. At the same time, environmental economists have also studied the relationship between urban spatial structures and environmental pollution. Glaeser and Khan found that per capita car use in high-density urban areas was lower, so the emissions of pollutants and carbon oxides were also lower [26]. Clark et al. argued that a centralized, single-center urban space structure could reduce the dependence on cars and energy consumption, thus curbing air pollution [27]. Rodríguez et al. investigated the relationship between local air pollution and urban structure with an emphasis on urban fragmentation, and the results of the econometric analysis support the hypothesis that urban structure has significant effects on pollution concentration [28]. Burgalassi and Luzzati summarized the possible links between spatial structure and emissions, and their results suggest that spatial structure affects $\mathrm{CO}_{2}$ emissions from private transport and particulate matters from housing emissions. There is no evidence for polycentricism to reduce emissions. [29]. In the study of Wang et al., $\mathrm{CO}_{2}$ emission efficiency is presented in terms of $\mathrm{CO}_{2}$ economic efficiency (CEE) and $\mathrm{CO}_{2}$ social efficiency (CSE). They calculated the CEE and CSE of nine cities in the Pearl River Delta and used panel data models to estimate the associations between urban form and $\mathrm{CO}_{2}$ emission efficiency, identifying a negative correlation between urban sprawl and CEE as well as CSE. [30].

To sum up, previous studies have analyzed the relationship between industrial agglomeration, urban sprawl, economic development, and environmental pollution in detail. On this basis, scholars at home and abroad have made great research achievements. However, the research dimension of the existing research is only to maintain the pairwise relationship analysis, and few studies have incorporated industrial agglomeration and urban sprawl into the same analytical framework. Meanwhile, most of the existing studies focus on the economic effect or environmental effect of industrial agglomeration and urban sprawl unilaterally, severing the connection between economic development and environmental protection. On the other hand, although some literature has discussed the environmental efficiency of the Beijing-Tianjin-Hebei urban agglomeration and its influencing factors [31-33], it has ignored the impact of industrial agglomeration and urban sprawl on the environmental efficiency. At present, China's development stage and implementation of development strategy mean that industrial agglomeration and urban sprawl are bound to have synergetic effects on urban environmental efficiency. In view of this fact, and based on the existing research, the Chinese national strategy of synergetic development of Beijing, Tianjin, and Hebei, and the panel data of 13 cities in the Beijing-Tianjin-Hebei urban agglomeration from 2006 to 2017, this paper empirically analyzes the internal relationship between urban sprawl, industrial agglomeration, and environmental efficiency, and puts forward feasible countermeasures and suggestions.

\section{Research Methods and Variables Description}

\subsection{Super Efficiency SBM Model with Undesirable Outputs}

Since the data envelopment analysis (DEA) method has the advantage of non-subjective empowerment, no effect of the input-output dimension, and can be used for the analysis of multi-input and multi-output efficiency, it is widely used in efficiency evaluation research [34]. However, 
the traditional DEA model is based on angles and orientations for efficiency measurement, and it is impossible to measure the efficiency problem when there are any undesirable outputs. Therefore, Tone [35] proposed a non-angle, non-oriented Slacks-based Measure (SBM) and constructed an SBM model that takes undesirable outputs into account.

Suppose there is a decision-making unit (DMU) in the production system, and each DMU has three input-output vectors, namely the input, expected output, and undesirable output. The elements can be expressed as $x \in R^{m}, y^{g} \in R^{s_{1}}$, and $y^{b} \in R^{s_{2}}$, respectively. The matrixes are defined as follows: $X=\left[x_{1}, x_{2}, \cdots, x_{n}\right] \in R^{m \times n}, Y^{g}=\left[y_{1}^{g}, y_{2}^{g}, \cdots, y_{n}^{g}\right] \in R^{s_{1} \times n}$, and $Y^{b}=\left[y_{1}^{b}, y_{2}^{b}, \cdots, y_{n}^{b}\right] \in R^{s_{2} \times n}$, with $X>0$, $Y^{g}>0, Y^{b}>0$. Then, the production possibility set can be defined as

$$
P=\left\{\left(x, y^{g}, y^{b}\right) \mid x \geq \lambda X, y^{g} \leq \lambda Y^{g}, y^{b} \geq \lambda Y^{b}, \lambda \geq 0\right\}
$$

In Formula (1), $\lambda$ is a weight vector. It should be pointed out that if the production technique is a variable return to scale, the constraint of $\lambda l=1$ is required, along with the vector $l$, whose elements are all 1, otherwise the production technique will be a constant return to scale.

Based on the definition of the production possibility set, the SBM model with undesirable outputs is as follows:

$$
\begin{gathered}
\rho^{*}=\min \frac{1-\frac{1}{m} \sum_{i=1}^{m} \frac{s_{i}^{-}}{x_{i 0}}}{1+\frac{1}{s_{1}+s_{2}}\left(\sum_{r=1}^{s_{1}} \frac{s_{r}^{g}}{y_{r 0}^{g}}+\sum_{r=1}^{s_{2}} \frac{s_{r}^{b}}{y_{r 0}^{b}}\right)} \\
\text { s.t. }\left\{\begin{array}{c}
x_{0}=\lambda X+s^{-} \\
y_{0}^{g}=\lambda Y^{g}-s^{g} \\
y_{0}^{b}=\lambda Y^{b}+s^{b} \\
s^{-} \geq 0, s^{g} \geq 0, s^{b} \geq 0, \lambda \geq 0
\end{array}\right.
\end{gathered}
$$

where $s$ indicates the amount of slack in the input and output; $\lambda$ represents the weight vector; and $\rho^{*}$ is the objective function, which is strictly decreasing about $s^{-}, s^{g}$ and $s^{b}$, accompanied by $0 \leq \rho^{*} \leq 1$. For a particular decision-making unit, if and only if $\rho^{*}=1$ (that is, $s^{-}=0, s^{g}=0$ and $s^{b}=0$ ), then it is efficient. If $\rho^{*}<1$, then the decision-making unit is inefficient and there is a need for improvement in input-output.

When the SBM model with undesirable outputs is evaluated for efficiency, there are often many efficient DMUs, which cannot be discriminated further as the efficiency scores of efficient DMUs are all 1. The super efficiency DEA model, which relaxes the restriction on the efficiency score to less than 1 , provides an efficiency rating of efficient units similar to the rating of inefficient units. Therefore, the super efficiency DEA theory [36] is introduced into model 2 to obtain a super efficiency SBM model with undesirable outputs:

$$
\begin{gathered}
\rho^{*}=\min \frac{1+\frac{1}{m} \sum_{i=1}^{m} \frac{s_{i}^{-}}{x_{i 0}}}{1-\frac{1}{s_{1}+s_{2}}\left(\sum_{r=1}^{s_{1}} \frac{s_{r}^{g}}{y_{r 0}^{g}}+\sum_{r=1}^{s_{2}} \frac{s_{r}^{b}}{y_{r 0}^{b}}\right)} \\
x_{0} \geq \lambda X+s^{-} \\
y_{0}^{g} \leq \lambda Y^{g}-s^{g} \\
y_{0}^{b} \geq \lambda Y^{b}+s^{b} \\
1-\frac{1}{s_{1}+s_{2}}\left(\sum_{r=1}^{s_{1}} \frac{s_{r}^{g}}{y_{r 0}^{g}}+\sum_{r=1}^{s_{2}} \frac{s_{r}^{b}}{y_{r 0}^{b}}\right)>0 \\
s^{-} \geq 0, s^{g} \geq 0, s^{b} \geq 0, \lambda \geq 0
\end{gathered} .
$$

The meaning of each variable in Formula (3) is consistent with Formula (2). To prevent the occurrence of the feasible solution in Formula (3), the equal sign in the constraint is replaced with the unequal sign. 


\subsection{Specification of the Tobit Regression Model}

According to the literature review, the economic and environment changes are closely related to the urban sprawl and industrial agglomeration, and China's current process of industrialization and urbanization promoting each other also determines that the interaction between urban sprawl and industrial agglomeration will have a synergetic effect on environmental efficiency. Therefore, based on the calculation of the environmental efficiency of 13 cities in the Beijing-Tianjin-Hebei urban agglomeration using the super-efficiency SBM model with undesirable outputs, and because the efficiency value is a censored dependent variable, this paper constructs the following panel Tobit regression model to further investigate the influence of urban sprawl and industrial agglomeration on environmental efficiency. The Tobit regression model was proposed by the Nobel laureate Tobin in 1958 [37]. When the dependent variables are partially continuous or partially discrete, the common method, ordinary least square (OLS), is no longer applicable to the regression analysis, and it may lead to deviation and inconsistency of the parameter estimators [38,39], so the Tobit model, which follows the maximum likelihood estimation method, becomes a better method to estimate the regression coefficient $[40,41]$ :

$$
\begin{aligned}
& \rho_{i, t}=\alpha_{0}+\alpha_{1} \operatorname{sprl}_{i, t}+\alpha_{2} \operatorname{aggl}_{i, t}+\alpha_{3} \operatorname{sprl} \cdot \operatorname{aggl} l_{i, t}+\alpha_{k} \sum_{k} X_{i, t}^{k}+\varepsilon_{i, t} \\
& \rho_{i, t}=\left\{\begin{array}{l}
\rho, \rho>0 \\
0, \rho<0
\end{array}\right.
\end{aligned}
$$

where $i$ represents the city; $t$ represents the year; the explained variable is the environmental efficiency $\rho$; the explanatory variables are the urban sprawl index sprl, the industrial agglomeration index aggl, and their cross terms sprl $\cdot a g g l ; X^{k}$ represents the other control variables; and $\alpha_{0}, \varepsilon$ are the intercept and random disturbance terms, respectively. Referring to these studies [42-44], the urban sprawl index is characterized by the ratio of the built-up area of municipal districts to the total population of municipal districts. The larger the value is, the higher the degree of the urban sprawl will be. The industrial agglomeration index is measured by the location entropy index according to the studies [45-47]. The specific calculation method is $a g g l_{i}=\left(e_{i, j} / e_{i}\right) /\left(E_{r, j} / E_{r}\right)$. In this formula, $i$ represents the city, $j$ represents the industry, $e_{i, j}$ is the gross product of industry $j$ in $i$ city, $e_{i}$ is the gross domestic product of $i$ city, $E_{r, j}$ is the gross product of industry $j$ in the Beijing-Tianjin-Hebei urban agglomeration, and $E_{r}$ is the gross domestic product of the Beijing-Tianjin-Hebei urban agglomeration. In this paper, the total industrial output value of each city in the Beijing-Tianjin-Hebei urban agglomeration is selected to calculate the location entropy to measure the degree of industrial agglomeration.

\subsection{Variables Description and Data Sources}

This paper takes 13 cities, including Beijing, Tianjin, Shijiazhuang, Chengde, Zhangjiakou, Qinhuangdao, Tangshan, Langfang, Baoding, Cangzhou, Hengshui, Xingtai, and Handan in the Beijing-Tianjin-Hebei urban agglomeration as the research objects. The research time ranges from 2006 to 2017-12 years in total. According to the above research methods, when calculating the environmental efficiency, we selected the fixed asset investment, labor, and energy consumption as inputs, and then we chose each city's GDP as the expected output indicators and the industrial wastewater, industrial $\mathrm{SO}_{2}$ emissions, and industrial smoke dust emissions as the undesirable output indicators. In the regression analysis of the econometric model, we selected each city's environmental efficiency as the explained variable, and urban sprawl and industrial agglomeration as the core explanatory variables and added the indicators of economic development, opening up to the outside world, industrial structure, urbanization level, and technological innovation as the control variables. The data of the economy, population, energy consumption, and pollution emissions of each city come from the statistical annals of Chinese cities; the statistical annals of China's energy resources; the statistical annals of Beijing, Tianjin, and Hebei; and the statistical annals and bulletins of Hebei cities in each year; these data are properly referred to. The specific explanations of each variable are as follows: 
(1) Explained variable. Taking the environmental efficiency of each city as the explained variable, which is calculated by the super-efficiency SBM model with undesirable outputs;

(2) Explanatory variables. Taking the urban sprawl index and the industrial agglomeration index as the core explanatory variables, which are calculated according to the methods described in the above economic model;

(3) Control variables. According to the environmental economics theory and the existing literature research, from the five aspects including economic development, opening up to the outside world, industrial structure, urbanization, and technological innovation, we respectively introduce the control variables. Economic development level $(e c o)$ is measured by the per capita GDP of each city; the opening up degree ( $f d i)$ is expressed as the proportion of the foreign direct investment in the GDP of each city, where the exchange rate of USD is calculated according to those years; industrial structure (ind) is represented by the proportion of tertiary industry's output value in GDP of each city; urbanization level (urb) is calculated by the proportion of urban population in the total population of each city; and technological innovation (tec) is measured by the proportion of R\&D expenditure in GDP of each city.

The detailed description and descriptive statistics of the above variables are shown in Table 1.

Table 1. Variable description and descriptive statistics.

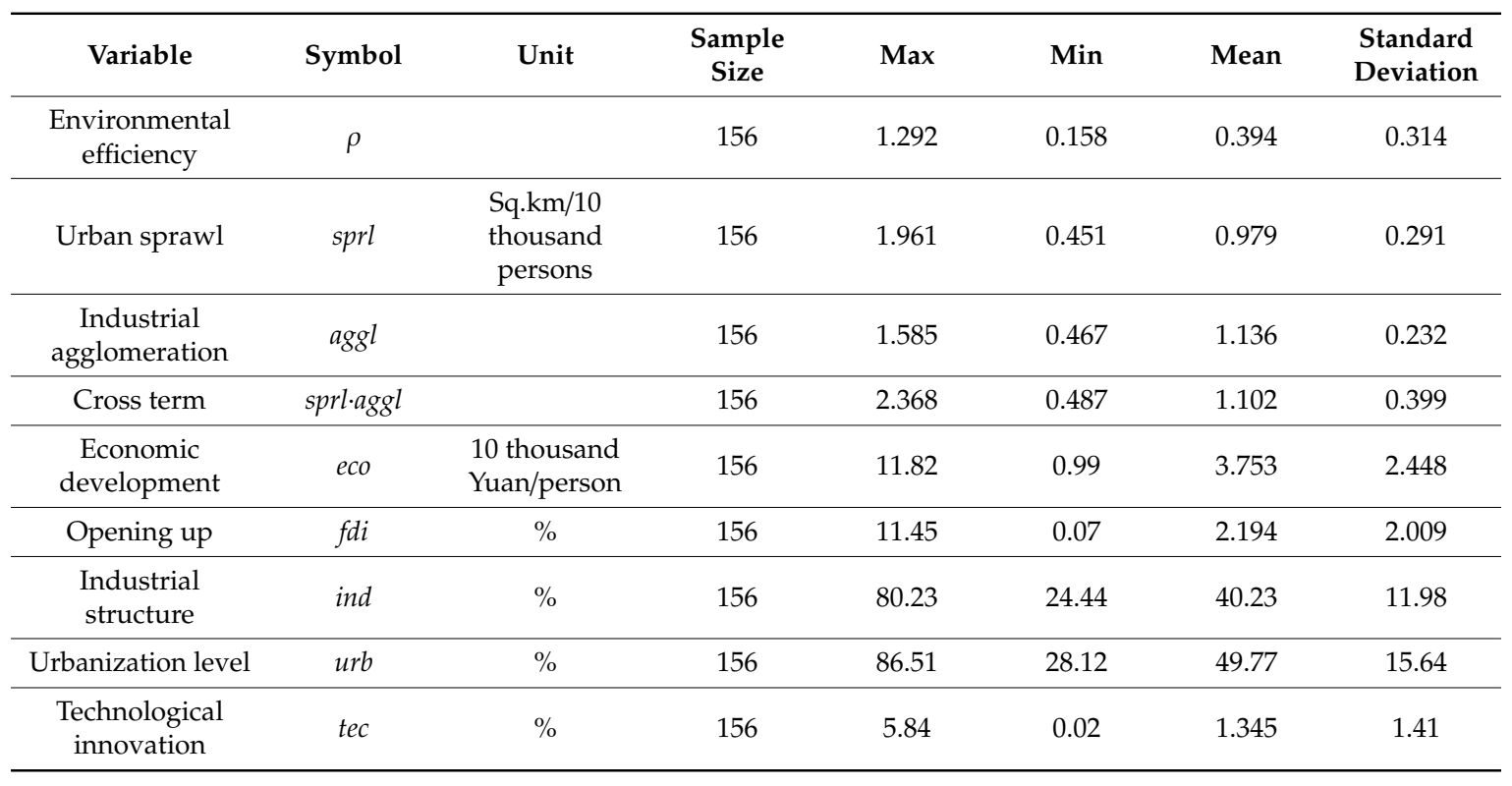

\section{Calculation Results and Analysis}

\subsection{Analysis of the Environmental Efficiency of the Beijing-Tianjin-Hebei Urban Agglomeration}

According to the super efficiency SBM model with the undesirable outputs mentioned above, the environmental efficiency of the Beijing-Tianjin-Hebei urban agglomeration from 2006 to 2017 is calculated by using the MAXDEA Ultra 7.9 software. The specific results are shown in Table 2.

Table 2. Environmental efficiency values of the Beijing-Tianjin-Hebei urban agglomeration.

\begin{tabular}{cccccccccccccc}
\hline City & $\mathbf{2 0 0 6}$ & $\mathbf{2 0 0 7}$ & $\mathbf{2 0 0 8}$ & $\mathbf{2 0 0 9}$ & $\mathbf{2 0 1 0}$ & $\mathbf{2 0 1 1}$ & $\mathbf{2 0 1 2}$ & $\mathbf{2 0 1 3}$ & $\mathbf{2 0 1 4}$ & $\mathbf{2 0 1 5}$ & $\mathbf{2 0 1 6}$ & $\mathbf{2 0 1 7}$ & Mean \\
\hline Beijing & 1.245 & 1.256 & 1.248 & 1.246 & 1.236 & 1.241 & 1.250 & 1.249 & 1.256 & 1.270 & 1.286 & 1.292 & 1.256 \\
Tianjin & 1.003 & 0.556 & 0.496 & 0.483 & 0.466 & 0.471 & 0.483 & 0.488 & 0.459 & 0.435 & 1.007 & 0.400 & 0.562 \\
Shijiazhuang & 0.313 & 0.307 & 0.289 & 0.274 & 0.268 & 0.255 & 0.259 & 0.250 & 0.232 & 0.239 & 0.250 & 0.231 & 0.264 \\
Chengde & 0.288 & 0.291 & 0.288 & 0.274 & 0.245 & 0.230 & 0.248 & 0.234 & 0.211 & 0.204 & 0.209 & 0.183 & 0.242 \\
Zhangjiakou & 0.363 & 0.310 & 0.282 & 0.246 & 0.217 & 0.203 & 0.200 & 0.192 & 0.179 & 0.182 & 0.185 & 0.165 & 0.227 \\
Qinhuangdao & 0.579 & 0.515 & 1.003 & 0.349 & 0.324 & 0.313 & 0.289 & 0.269 & 0.249 & 0.254 & 0.260 & 0.235 & 0.387 \\
\hline
\end{tabular}


Table 2. Cont.

\begin{tabular}{cccccccccccccc}
\hline City & $\mathbf{2 0 0 6}$ & $\mathbf{2 0 0 7}$ & $\mathbf{2 0 0 8}$ & $\mathbf{2 0 0 9}$ & $\mathbf{2 0 1 0}$ & $\mathbf{2 0 1 1}$ & $\mathbf{2 0 1 2}$ & $\mathbf{2 0 1 3}$ & $\mathbf{2 0 1 4}$ & $\mathbf{2 0 1 5}$ & $\mathbf{2 0 1 6}$ & $\mathbf{2 0 1 7}$ & Mean \\
\hline Tangshan & 1.036 & 1.046 & 1.015 & 0.381 & 0.343 & 0.340 & 0.371 & 0.350 & 0.321 & 0.305 & 0.302 & 0.257 & 0.506 \\
Langfang & 0.316 & 0.295 & 0.274 & 0.248 & 0.239 & 0.281 & 0.268 & 0.261 & 0.241 & 0.254 & 0.274 & 0.254 & 0.267 \\
Baoding & 0.305 & 0.313 & 0.305 & 0.268 & 0.263 & 0.247 & 0.245 & 0.235 & 0.218 & 0.229 & 0.242 & 0.217 & 0.257 \\
Cangzhou & 1.037 & 1.017 & 0.363 & 0.318 & 0.320 & 0.310 & 0.289 & 0.264 & 0.239 & 0.240 & 0.248 & 0.217 & 0.405 \\
Hengshui & 0.277 & 0.295 & 1.010 & 0.287 & 0.259 & 0.243 & 0.246 & 0.231 & 0.202 & 0.210 & 0.213 & 0.202 & 0.306 \\
Xingtai & 0.269 & 0.269 & 0.243 & 0.212 & 0.202 & 0.193 & 0.203 & 0.189 & 0.168 & 0.169 & 0.175 & 0.158 & 0.204 \\
Handan & 0.313 & 0.321 & 0.288 & 0.256 & 0.240 & 0.229 & 0.232 & 0.221 & 0.192 & 0.188 & 0.191 & 0.163 & 0.236 \\
Mean & 0.565 & 0.522 & 0.546 & 0.372 & 0.356 & 0.350 & 0.353 & 0.341 & 0.321 & 0.321 & 0.372 & 0.306 & \\
\hline
\end{tabular}

From the results of Table 2, we can see that only Beijing's environmental efficiency mean is greater than 1 in the 13 cities of the Beijing-Tianjin-Hebei urban agglomeration and far higher than the other cities, which suggests that Beijing's environment is in the production frontier and can reasonably control the relationship between economic development and environmental protection, while the other cities' environmental efficiency has failed to achieve the production frontier. From the mean values of the other cities' environmental efficiency, Tianjin's and Tangshang's efficiency values are above 0.5, which means that their environmental efficiency level is relatively high, but there is still some room for improvement. The environmental efficiency level of Qinhuangdao, Cangzhou, and Hengshui is relatively general, with an average value of around 0.4. However, the efficiency values of Shijiazhuang, Chengde, Zhangjiakou, Langfang, Baoding, Xingtai, and Handan are relatively low, none of which exceed 0.3. It can be seen that the cities' environmental efficiency levels in the Beijing-Tianjin-Hebei urban agglomeration differ significantly, and the cities with a higher efficiency are those with a more developed regional economic development level, such as Beijing and Tianjin, whereas in the process of industrialization and urbanization, the cities with a lower efficiency have promoted economic development at the expense of environmental protection. In future development processes, how to effectively improve the environmental efficiency and give consideration to environmental protection and economic development will be important issues faced by these cities.

The change of the average environmental efficiency of the Beijing-Tianjin-Hebei urban agglomeration from 2006 to 2017 shows an obvious downward trend, and the mean value decreases from 0.565 in 2006 to 0.306 in 2017 . This result is mainly due to the fact that the environmental efficiency of the cities in Hebei province has decreased, possibly because, compared with Beijing and Tianjin, the cities' economic development is relatively slow and their urbanization degree is relatively low in the process of new industrialization and urbanization, and these cities still rely on the economic development model of high inputs, high consumption, and high emissions, which have resulted in a decrease of the overall environmental efficiency of the Beijing-Tianjin-Hebei urban agglomeration during this period. The Environmental Kuznets Curve shows that in the process of economic development, environmental quality will decline with economic growth and will increase with economic growth when the economic level reaches a certain level. In the "eleventh five-year" and "twelfth five-year" period, China was in the process of vigorously promoting industrialization and urbanization, and the decline of environmental efficiency in the Beijing-Tianjin-Hebei urban agglomeration also confirms this conclusion. Although the current stage is inevitable, environmental problems cannot be ignored. Therefore, on the basis of clarifying the changes of environmental efficiency, it is of great significance to analyze the impact of urban sprawl, industrial agglomeration, and other factors on the environmental efficiency for working out how to effectively promote the improvement of environmental efficiency in the synergetic development of the Beijing-Tianjin-Hebei region.

\subsection{Influential Factors Analysis of Environmental Efficiency}

To explore the impact of urban sprawl and industrial agglomeration on the environmental efficiency, this paper takes the data of 13 cities in the Beijing-Tianjin-Hebei urban agglomeration from 2006 to 2017 as the study sample, according to the above formula (4), and we have introduced the core explanatory variables to construct the panel Tobit regression model. With the help of 
Eviews 10.0 software, the panel Tobit regression model is estimated by using the maximum likelihood estimation method. The specific results are shown in Table 3.

Table 3. The panel Tobit regression results of the Beijing-Tianjin-Hebei urban agglomeration.

\begin{tabular}{ccccc}
\hline Variables & Coefficient & Std.Error & z-Statistic & Prob. \\
\hline sprl & $-1.232^{* * *}$ & 0.528 & -2.806 & 0.005 \\
aggl & $1.726^{* * *}$ & 0.539 & 3.205 & 0.001 \\
sprl.aggl & $1.437^{* * *}$ & 0.644 & 3.597 & 0.000 \\
eco & $-0.035^{* *}$ & 0.012 & -2.334 & 0.020 \\
fdi & $0.015^{*}$ & 0.009 & 1.663 & 0.096 \\
ind & $0.016^{* *}$ & 0.004 & 2.232 & 0.026 \\
urb & -0.003 & 0.003 & -1.001 & 0.315 \\
tec & $0.165^{* * *}$ & 0.019 & 8.774 & 0.000 \\
Constant & $-2.259^{* * *}$ & 0.701 & -3.224 & 0.001 \\
S.E. of regression & 0.166 & & & \\
Log likelihood & 62.757 & & & \\
Akaike info criterion & -0.676 & & \\
Schwarz criterion & -0.481 & & \\
\hline Note: ${ }^{*}, * *$ and ${ }^{* * *}$ denote significance within the levels of $10 \%, 5 \%$, and $1 \%$, respectively.
\end{tabular}

From the results of Table 3, it can be seen that the standard error of regression is 0.166 and the Log likelihood is 62.757, which indicates that the Tobit regression model can better explain the relationship between urban sprawl, industrial agglomeration, and environmental efficiency of the Beijing-Tianjin-Hebei urban agglomeration. By introducing the core explanatory variables and the control variables, the regression results show that except for the insignificance of the variable of urbanization, the other variables have a significant impact on environmental efficiency, at least at the level of $10 \%$ significance. From the regression results of the core explanatory variables, all the $\mathrm{P}$ values are less than 0.01 , and the coefficient of the urban sprawl is -1.232 , which indicates that there is a significantly negative correlation between urban sprawl and environmental efficiency, where every $1 \%$ increase in urban sprawl will lead to a $1.232 \%$ decrease in environmental efficiency. However, the industrial agglomeration has a significantly positive impact on environmental efficiency; if industrial agglomeration increases by $1 \%$, environmental efficiency will increase by $1.726 \%$. When introducing the cross term of urban sprawl and industrial agglomeration, the coefficient of the cross term is 1.437, which is significantly positive, indicating that the synergetic effect of them has a promoting effect on environmental efficiency, and with the continuous improvement of industrial agglomeration, the negative effect of urban sprawl will be partially offset. The reason for this may be that most cities in the Beijing-Tianjin-Hebei agglomeration are presently in the stage of rapid urbanization, and urban sprawl makes urban space expand rapidly but also leads to some problems, such as farmland embezzlement, greening encroachment, and more reliance on automobile traffic, which damage the ecological environment. Additionally, industrial agglomeration can effectively integrate the allocation of urban factor resources, attract more talents to the cities, give full play to its scale economy effect and technology spillover effect, accelerate technological innovation, and improve energy efficiency, thus promoting the improvement of environmental quality.

According to the results of each control variable, the influence of economic development on environmental efficiency is significantly negative, which indicates that the Beijing-Tianjin-Hebei agglomeration has not yet crossed the peak of the environmental Kuznets curve. Meanwhile, the influence of opening up on environmental efficiency is positive at the level of $10 \%$ significance, and this result means that the "pollution paradise" hypothesis in the Beijing-Tianjin-Hebei agglomeration is false. The influence coefficient of industrial structure is significantly positive, which shows that the increase of the proportion of tertiary industry is conducive to improving environmental efficiency, and upgrading industrial structure is an important way to optimize the ecological environment of the Beijing-Tianjin-Hebei urban agglomeration. Urbanization level has 
an insignificantly negative correlation with environment efficiency, and the reason for this is that, at present, most cities in the Beijing-Tianjin-Hebei urban agglomeration have an extensive urbanization development mode and only pursue the speed of development, while ignoring the problems brought by rapid urbanization development, such as the accumulation of human capital, the intensification of energy consumption, the increase of traffic demand, and serious industrial pollution. Technological innovation has a significant promoting effect on environmental efficiency, because not only can technological innovation improve the production efficiency [48], but the progress of clean production technology can also effectively control the consumption of resources and energy, reduce pollution emissions [49,50], and improve environmental efficiency.

\section{Conclusions and Policy Implications}

\subsection{Main Conclusions}

Based on the data of 13 cities in the Beijing-Tianjin-Hebei urban agglomeration from 2006 to 2017, this paper measures and analyzes the environmental efficiency of the Beijing-Tianjin-Hebei urban agglomeration by using the super efficiency SBM model with undesirable outputs. On this basis, this paper empirically studies the internal relation between urban sprawl, industrial agglomeration, and environmental efficiency by using the panel data model. The main findings are as follows:

(1) During the study period, there existed distinct differences in the environmental efficiency levels of the Beijing-Tianjin-Hebei urban agglomeration. Except for Beijing's environmental efficiency exhibiting a full efficiency, the environmental efficiency of other cities needs to be improved. From the overall performance, the environmental efficiency of the Beijing-Tianjin-Hebei urban agglomeration showed an obvious downward trend. In the synergetic development of the Beijing-Tianjin-Hebei region, how to effectively improve the environmental efficiency and give consideration to both environmental protection and economic development is an important issue facing the Beijing-Tianjin-Hebei urban agglomeration;

(2) The empirical analysis showed that urban sprawl had a significantly negative impact on the environmental efficiency of the Beijing-Tianjin-Hebei urban agglomeration. Industrial agglomeration had a significantly positive influence on environmental efficiency. The synergetic effect of the two could promote environmental efficiency. With the continuous improvement of industrial agglomeration, the negative effects of urban sprawl on environmental efficiency would be partially offset;

(3) The other influencing factors of environmental efficiency showed that economic growth and urbanization hindered the promotion of the environmental efficiency of the Beijing-Tianjin-Hebei urban agglomeration, but the optimization of industrial structure and the increase of technological innovation level were conducive to the improvement of environmental efficiency. The positive impact of opening up to the outside world on the environmental efficiency was significant, and the "pollution paradise" hypothesis was untenable.

\subsection{Policy Implications}

Through the above conclusions, the policy implications are as follows.

Firstly, in view of the large differences of environmental efficiency between the cities in the Beijing-Tianjin-Hebei urban agglomeration, differentiated industrial and environmental policies should be implemented in the process of promoting the Beijing-Tianjin-Hebei synergetic development strategy. The cities with a high environmental efficiency can be encouraged to vigorously develop clean production technologies and focus on developing emerging high-tech industries in the future. For the cities with a low environmental efficiency, we should continue to promote the optimization and upgrading of industrial structures and eliminate a backward production capacity. Secondly, in order to reduce the impact of urban sprawl, changes should be made to the urbanization development strategy to avoid over-emphasizing the speed of urbanization. Instead, while increasing the urbanization 
rate, we should pay more attention to the quality of the development of cities and towns, effectively controlling the disorderly sprawl of the urban scale so as to form a reasonable layout of urban space. Finally, taking the development of industrial agglomeration as the starting point, we will carry out macro-control over the industrial space of the Beijing-Tianjin-Hebei urban agglomeration, actively exert the effects of scale economies and technology spillover from industrial agglomeration, change the development mode of labor-intensive and low-end processing in small- and medium-sized cities, accelerate the promotion of high-end industrial agglomeration and the upgrading of the industrial chain, and break through the bottleneck of the ecological environment relying on technological progress.

Author Contributions: All authors contributed equally to this work. Specifically, D.F. developed the original idea for the study and designed the methodology. X.L. completed in the survey and drafted the manuscript, which was revised by L.L. and Z.Z. All authors read and approved the final manuscript.

Funding: This research was funded by: The National Social Science Foundation of China, Research on the Generating Mechanism Evaluation Method and Governance Model of the Political Cost of Environmental Pollution Problem, No. 16BGL138; the Key Projects of Philosophy and Social Science in Ministry of Education, Study on Some Major Issues in the Implementation of the Beijing-Tianjin-Hebei Synergetic Development Strategy, No. 15JZD021.

Conflicts of Interest: The authors declare no conflict of interest.

\section{References}

1. Yao, X.L.; Kou, D.; Shao, S.; Li, X.Y.; Wang, W.X.; Zhang, C.T. Can urbanization process and carbon emission abatement be harmonious? New evidence from China. Environ. Impact Assess. Rev. 2018, 71, 70-83. [CrossRef]

2. Zhang, G.L.; Zhang, N.; Liao, W.M. How do population and land urbanization affect $\mathrm{CO}_{2}$ emissions under gravity center change? A spatial econometric analysis. J. Clean. Prod. 2018, 202, 510-523. [CrossRef]

3. Chen, N.C.; Xu, L.; Chen, Z.Q. Environmental efficiency analysis of the Yangtze River Economic Zone using super efficiency data envelopment analysis (SEDEA) and tobit models. Energy 2017, 134, 659-671. [CrossRef]

4. Zhuang, M.; Sheng, J.C.; Webber, M.; Baležentis, T.; Geng, Y.; Zhou, W. Measuring water use performance in the cities along China's South-North water transfer project. Appl. Geogr. 2018, 98, 184-200.

5. Yang, Y.; Zhou, Y.N.; Poon, J.; He, Z. China's carbon dioxide emission and driving factors: A spatial analysis. J. Clean. Prod. 2019, 211, 640-651. [CrossRef]

6. Han, R.; Tang, B.J.; Fan, L.J.; Liu, L.C.; Wei, Y.M. Integrated weighting approach to carbon emission quotas: An application case of Beijing-Tianjin-Hebei region. J. Clean. Prod. 2016, 131, 448-459. [CrossRef]

7. Shen, N.; Zhao, Y.Q.; Wang, Q.W. Diversified agglomeration, specialized agglomeration, and emission reduction effect- A nonlinear test based on Chinese city data. Sustainability 2018, 10, 2002. [CrossRef]

8. Blasio, G.; Addrio, S. Do workers benefit from industrial agglomeration. J. Reg. Sci. 2005, 45, 797-827. [CrossRef]

9. Drucker, J.; Feser, E. Regional industrial structure and agglomeration economies: An analysis of productivity in three manufacturing industries. Reg. Sci. Urban Econ. 2012, 42, 1-14. [CrossRef]

10. Cainelli, G.; Ganau, R.; Giunta, A. Spatial agglomeration, global value chains, and productivity. Micro-evidence from Italy and Spain. Econ. Lett. 2018, 169, 43-46. [CrossRef]

11. Ning, L.T.; Wang, F.; Li, J. Urban innovation, regional externalities of foreign direct investment and industrial agglomeration: Evidence from Chinese cities. Res. Policy 2016, 45, 830-843. [CrossRef]

12. Harris, J. The messy reality of agglomeration economies in urban informality: Evidence from Nairobi's handicraft industry. World Dev. 2014, 61, 102-113. [CrossRef]

13. Lu, J.Y.; Tao, Z.G. Trends and determinants of China's industrial agglomeration. J. Urban Econ. 2009, 65, 167-180. [CrossRef]

14. Glaeser, E.; Kahn, M. Chapter 56-Sprawl and urban growth. Handb. Reg. Urban Econ. 2004, 4, 2481-2527.

15. Fallah, B.; Partridge, M.; Olfert, M. Urban sprawl and productivity: Evidence from US metropolitan. Papers Reg. Sci. 2011, 90, 451-472. [CrossRef]

16. Henderson, J.; Storeygard, A.; Weil, D. Measuring economic growth from outer space. Am. Econ. Rev. 2012, 102, 994-1028. [CrossRef] [PubMed]

17. Navamuel, E.; Morollon, F.; Cuartas, B. Energy consumption and urban sprawl: Evidence for the Spanish case. J. Clean. Prod. 2018, 172, 3479-3486. [CrossRef] 
18. Grossman, G.; Krueger, A. Economic growth and the environment. Q. J. Econ. 1995, 110, 353-377. [CrossRef]

19. Lin, B.Q.; Liu, X.Y. China's carbon dioxide emissions under the urbanization process: Influence factors and abatement policies. Econ. Res. J. 2010, 8, 66-78. (In Chinese)

20. Frank, A.; Moussiopoulos, N.; Sahm, P. Urban air quality in larger conurbations in the European Union. Environ. Model. Softw. 2001, 16, 399-414.

21. Ottaviano, G.; Tabuchi, T.; Thisse, J. Agglomeration and trade revisited. Int. Econ. Rev. 2002, 43, 409-436. [CrossRef]

22. Zeng, D.L.; Zhao, L.X. Pollution havens and industrial agglomeration. J. Environ. Econ. Manag. 2009, 58, 141-153. [CrossRef]

23. Liu, J.; Cheng, Z.H.; Zhang, H.M. Does industrial agglomeration promote the increase of energy efficiency in China. J. Clean. Prod. 2017, 164, 30-37. [CrossRef]

24. Zhao, H.L.; Lin, B.Q. Will agglomeration improve the energy efficiency in China's textile industry: Evidence and policy implications. Appl. Energy 2019, 237, 326-337. [CrossRef]

25. Wang, Y.P.; Yan, W.L.; Ma, D.; Zhang, C.L. Carbon emissions and optimal scale of China's manufacturing agglomeration under heterogeneous environmental regulation. J. Clean. Prod. 2018, 176, 140-150. [CrossRef]

26. Glaeser, E.; Khan, M. The greenness of cities: Carbon dioxide emissions and urban development. J. Urban Econ. 2010, 67, 404-418. [CrossRef]

27. Clark, L.; Millet, D.; Marshall, J. Air quality and urban form in US urban areas: Evidence from regulatory monitors. Environ. Sci. Technol. 2011, 45, 7028-7035. [CrossRef] [PubMed]

28. Rodríguez, M.; Courtade, L.; Oueslati, W. Air pollution and urban structure linkage: Evidence from European cities. Renew. Sustain. Energy Rev. 2016, 53, 1-9. [CrossRef]

29. Burgalassi, D.; Luzzati, T. Urban spatial structure and environmental emissions: A survey of the literature and some empirical evidence for Italian NUTS 3 regions. Cities 2015, 49, 134-148. [CrossRef]

30. Wang, S.J.; Wang, J.Y.; Fang, C.L.; Li, S.J. Estimating the impacts of urban form on $\mathrm{CO}_{2}$ emission efficiency in the Pearl River Delta, China. Cities 2019, 85, 117-129. [CrossRef]

31. Li, J.C.; Xiang, Y.W.; Jia, H.Y.; Chen, L. Analysis of total factor energy efficiency and its influencing factors on key energy-intensive industries in the Beijing-Tianjin-Hebei region. Sustainability 2018, 10, 111. [CrossRef]

32. Feng, D.; Li, J. Research of the carbon dioxide emission efficiency and reduction potential of cities in the Beijing-Tianjin-Hebei region. Resour. Sci. 2017, 39, 978-986. (In Chinese)

33. Wen, J.S.; Wang, H.Y.; Chen, F.X.; Yu, R.N. Research on environmental efficiency and TFP of Beijing areas under constraint of energy-saving and emission reduction. Ecol. Indic. 2018, 84, 235-243. [CrossRef]

34. Yang, Q.; Wang, X.; Baležentis, T.; Streimikiene, D. Energy-economy-environmental (3E) performance of Chinese regions based on the data envelopment analysis model with mixed assumptions on disposability. Energy Environ. 2018, 29, 664-684.

35. Tone, K. A Slacks-based measure of Efficiency in Data Envelopment Analysis. Eur. J. Oper. Res. 2001, 130, 498-509. [CrossRef]

36. Anderson, P.; Petersen, N. A Procedure for Ranking Efficient Units in Data Envelopment Analysis. Manag. Sci. 1993, 39, 1261-1264. [CrossRef]

37. Tobin, J. Estimation of relationships for limited dependent variables. Econometrica 1958, 26, 24-36. [CrossRef]

38. Sağlam, Ü. A two-stage performance assessment of utility-scale wind farms in Texas using data envelopment analysis and Tobit models. J. Clean. Prod. 2018, 201, 580-598. [CrossRef]

39. Liu, J.; Zhang, J.F.; Fu, Z.B. Tourism eco-efficiency of Chinese coastal cities-Analysis based on the DEA-Tobit model. Ocean Coast. Manag. 2017, 148, 164-170. [CrossRef]

40. Hafner, C.M.; Preminger, A. A note on the Tobit model in the presence of a duration variable. Econ. Lett. 2015, 126, 47-50. [CrossRef]

41. Yang, Z.S.; Wei, X.X. The measurement and influences of China's urban total factor energy efficiency under environmental pollution: Based on the game cross-efficiency DEA. J. Clean. Prod. 2019, 209, 439-450. [CrossRef]

42. Jiang, Z.X.; Zhang, W.D.; Li, Y.Z. Based on the location entropy method to study the agglomeration development of the software industry of Jilin Province. Adv. Mater. Res. 2014, 998, 1075-1078. [CrossRef]

43. Li, C.X.; Wu, K.N.; Gao, X.Y. Manufacturing industry agglomeration and spatial clustering: Evidence from Hebei province, China. Environ. Dev. Sustain. 2019, 2, 1-25. [CrossRef] 
44. Zheng, Q.Y.; Lin, B.Q. Impact of industrial agglomeration on energy efficiency in China's paper industry. J. Clean. Prod. 2018, 184, 1072-1080. [CrossRef]

45. Horn, A.; Van Eeden, A. Measuring sprawl in the Western Cape province, South Africa: An urban sprawl index for comparative purposes. Reg. Sci. Policy Pract. 2018, 10, 15-23. [CrossRef]

46. Li, T.; Li, Y.F.; Yan, Y.Q.; Wang, B.Y. Measuring urban sprawl and exploring the role planning plays: A Shanghai case study. Land Use Policy 2017, 67, 426-435.

47. Jaeger, J.; Bertiller, R.; Schwick, C.; Kienast, F. Suitability criteria for measures of urban sprawl. Ecol. Indic. 2010, 10, 397-406. [CrossRef]

48. Shen, Z.; Baležentis, T.; Chen, X.; Valdmanis, V. Green growth and structural change in Chinese agricultural sector during 1997-2014. China Econ. Rev. 2018, 51, 83-96. [CrossRef]

49. Yan, Q.; Wang, Y.; Baležentis, T.; Sun, Y.; Streimikiene, D. Energy-Related $\mathrm{CO}_{2}$ Emission in China's Provincial thermal electricity generation: Driving factors and possibilities for abatement. Energies 2018, 11, 1096. [CrossRef]

50. Chen, J.; Zhao, A.; Zhao, Q.; Song, M.; Baležentis, T.; Streimikiene, D. Estimation and factor decomposition of carbon emissions in China's tourism sector. Probl. Ekorozw. 2018, 13, 91-101.

(C) 2019 by the authors. Licensee MDPI, Basel, Switzerland. This article is an open access article distributed under the terms and conditions of the Creative Commons Attribution (CC BY) license (http://creativecommons.org/licenses/by/4.0/). 